\title{
Psychological Health Correlates of Perceived Discrimination among Canadian Gay Men and Lesbian Women
}

\author{
Melanie A. Morrison \\ University of Saskatchewan
}

\begin{abstract}
Despite the growing number of studies investigating the association between perceived discrimination and psychological health, research of this kind is scarce in Canada. To begin addressing this omission, the present study documents the frequency of discriminatory events experienced by sexual minorities and their linkage with indicants of psychological well-being. Responding to an online survey, 348 self-identifying gay men $(n=177)$ and lesbian women $(n=169)$ completed measures of perceived discrimination, depression, psychological distress, life optimism, and self-esteem. Perceiving verbal insults and verbal threats were the most frequently cited incidents, and several statistically significant correlates of depression and psychological distress emerged. Exploratory analyses revealed that: (a) the association between depression and internalized homonegativity was greater in magnitude for lesbian women than for gay men; and (b) the associations between being the recipient of verbal insults and depression and psychological distress were greater for gay men than lesbian women. Limitations of the study and directions for future research are outlined.
\end{abstract}

Keywords: gay men, lesbian women, prejudice, discrimination, stigma, health, homonegativity, homophobia, Canada

According to Pascoe and Richman (2009), perceived discrimination is a "behavioral manifestation of a negative attitude, judgment, or unfair treatment toward members of a group" (p. 533). The authors contend that individuals who perceive discrimination will most often experience concomitant forms of stress. In their meta-analysis on the relationship between perceived discrimination and mental and physical health outcomes $(k=134)$, perceived discrimination was positively related to mental and physical health impairments such as depression, psychiatric distress, and cardiovascular disease risk factors. Gender and ethnicity (i.e., Asian,

Melanie A. Morrison, PhD, Department of Psychology, University of Saskatchewan.

This work was supported by a Saskatchewan Health Research Foundation Grant (grant no. 1552). I would like to acknowledge all of the participants who took the time to complete questionnaires and provide insightful comments about the research.

Correspondence concerning this article should be addressed to Melanie A. Morrison, Department of Psychology, University of Saskatchewan, Saskatoon, SK, S7N 5A5. Email: melanie.morrison@usask.ca. 
Black, Hispanic, Native American, and White) did not emerge as moderator variables (i.e., the relationship between perceived discrimination and mental and physical health outcomes was comparable for men and women and ethnocultural groups).

Over the past decade, the number of studies examining perceived interpersonal or institutional discrimination on the basis of sexual orientation and their relationship to psychological and physical health variables has increased (e.g., Fingerhut, Peplau, \& Gable, 2010; Hatzenbuehler, McLaughlin, Keyes, \& Hasin, 2010; Mays \& Cochran, 2001). Much of this research, and that examining within-group differences among various categories of sexual minorities (e.g., mental health outcomes of gay men who have versus have not been victimized) are framed within a minority stress perspective (Meyer, 2003a, 2003b). According to this perspective, members of stigmatized social groups are subject to conflict between themselves and the dominant culture. This conflict may, in turn, produce a significant number of social stressors, which range along a continuum from distal sources (i.e., objective events and conditions such as discrimination and violence) to proximal sources (i.e., subjective processes involving cognitive perceptions and appraisals such as internalized homonegativity). Both categories of stressor may compromise the psychological and physical wellness of gay men and lesbian women (Meyer, 2003b).

Although research on discrimination experiences and psychological health is growing steadily (see Hatzenbuehler, 2009; and Savin-Williams, 2001), one country that has surprisingly little representation in this corpus of work is Canada. Indeed, the author of the current study is unaware of any published research that has examined Canadian gay and lesbian adults' perceived discrimination and its relationship with psychological health. At present, the majority of the published research has been produced in the United States. The monocultural nature of this work is problematic because researchers have outlined points of divergence between Canada and the United States vis-à-vis the countries' treatment of sexual minorities. Specifically: (a) national legislation according same-sex individuals the right to be legally married exists in Canada; (b) fewer Canadians (6\%) than Americans (22\%) self-identify as evangelical Protestants, a group that is vociferous in its opposition to gay and lesbian equality (Adam, 1999); (c) a larger proportion of Canadians are members of unions - sites that have, in the past, promoted protection for individuals on the basis of sexual orientation (Adam, 1999); (d) Canada lacks the militaristic traditions evidenced in American society that, according to Adam, "bind the national identity with homophobic panic" (p. 17); and (e) due to the continued existence of Anglophone and Francophone cultures, Canada has not experienced the same degree of white, Anglo-Saxon, Protestant cultural hegemony apparent in the United States.

Given such differences, it is possible that gay and lesbian Canadians are subject to less minority stress and resultant sequelae than their American counterparts. Thus, the first objective of this study was to document the prevalence of discriminatory events experienced by a convenience sample of Canadian adults who self-identify as gay or lesbian. The second objective was to investigate the relationship between perceived discrimination and indicants of psychological well-being. On the basis of the literature from American studies (e.g., Chae et al., 2010; Cochran \& Mays, 2007; D’Augelli, 2003; D’Augelli \& Grossman, 2001; Meyer, 2003b; Roberts, Austin, Corliss, Vandermorris, \& Koenen, 2010), the following hypotheses were tested:

1. Verbal insults and verbal threats will be the most frequently cited discriminatory events.

2. Perceived discrimination will correlate positively with depression and psychological distress.

3. Perceived discrimination will correlate negatively with life optimism and self-esteem. 
PSYCHOLOGICAL, HEALTH CORRELATES

\section{METHOD}

\section{Participants}

Participants were 348 self-identifying men $(n=177)$ and women $(n=169)$ born and currently residing in Canada. Two participants did not provide their gender. The age range for participants was 18 to 78 years $(M=35.65 ; S D=12.96)$, with similar values emerging for gay men $(M=36.97 ; S D=13.99$; range from 18 to 78 years) and lesbian women $(M=34.33 ; S D=11.72$; range from 18 to 72 years [men's and women's ages did not differ significantly.]). Approximately $96 \%$ of men and $87 \%$ of women self-identified as "exclusively" or "primarily" homosexual. In terms of ethnicity, a majority (i.e., 89\%) self-identified as Caucasian, suggesting that minimal representation was obtained from other ethno-cultural communities (e.g., Aboriginal, Asian, Black, or Hispanic). When asked to indicate their relationship status, approximately $43 \%$ of the gay male respondents indicated they were dating, living with a partner, or married. For lesbian women, this proportion was $60 \%$. Approximately $66 \%$ of gay and lesbian participants indicated being "highly" or "moderately" integrated into gay/lesbian culture.

Although not an explicit focus of the current study, details about smoking behaviour and alcohol consumption were obtained to further contextualize the health status of the sample. Twenty-eight percent of gay men and $24 \%$ of lesbian women indicated that they smoke, with the mean number of cigarettes smoked per day being 12 and 10, respectively. A majority of participants reported consuming alcohol in the past month ( $84 \%$ of gay men; $79 \%$ of lesbian women). Of the 128 men $(72.3 \%)$ who indicated consuming five or more drinks on separate occasions within the past month, they did so, on average, 2.9 times. For lesbian women ( $n=111 ; 65.7 \%$ ), this level of "binge-drinking" occurred, on average, two times during the past month.

\section{Measures}

Center for Epidemiological Studies on Depression Scale (CES-D). The CES-D (Radloff, 1977) is a 20 -item measure on which respondents rate the frequency of various depressive symptoms that have occurred during the previous week. Sample items include: "I felt depressed" and "All in all, I am inclined to feel that I am a failure." In the present study, a 4-point Likert-type scale was used $(0=$ not even 1 day; $1=1-2$ days; $2=3-4$ days; $3=5-7$ days). Scores range from 0 to 60 , with higher scores indicating greater depression. The CES-D has been shown to be reliable and valid (e.g., Lewinsohn, Seeley, Roberts, \& Allen, 1997).

Hopkins Symptom Checklist-21 (HSCL-21). The HSCL-21 (Green, Walkey, McCormick, \& Taylor, 1988) consists of 21 items from the original 58-item version (Derogatis, Lipman, Rickels, Uhlenhuth, \& Covi, 1974) and measures general psychological distress. The HSCL-21 asks participants "how they have felt in the previous 7 days including today" and instructs them to rate how distressing they find each item using a 4-point response format $(0=$ not at all; $1=$ a little; $2=$ quite a bit; 3 =extremely $)$. Sample items include "Blaming yourself for things" and "Having to do things very slowly in order to be sure you're doing them right." Scores range from 0 to 63 , with higher scores indicating greater levels of psychological distress. Research by Green et al. (1988) and Cepeda-Benito and Gleaves (2000) attests to the psychometric soundness of the HSCL-21.

Life Optimism Test (LOT). The LOT (Scheier \& Carver, 1985) measures optimism in adults and contains a total of 12 items ( 4 of which are filler). Representative items include "I always look on the bright 
side of things" and "In uncertain times, I usually expect the best." Participants were instructed to respond to each item using a 5 -point Likert-type scale $(1=$ strongly disagree; $2=$ disagree; $3=$ unsure; $4=$ agree; $5=$ strongly agree). Scores range from 12 to 60 , with higher scores indicating greater life optimism. Scheier and Carver (1985) provide evidence in support of the LOT's scale score reliability and validity.

Rosenberg Self-Esteem Scale (RSES). The RSES (Rosenberg, 1965) measures global self-esteem and consists of 10 items (e.g., "I am able to do things as well as most other people" and "I feel that I am a person of worth, at least on an equal plane with others"). Participants were instructed to respond to each item using a 5-point Likert-type scale ( 1 = strongly disagree; 2 = disagree; $3=$ don't know; $4=$ agree $; 5=$ strongly agree $)$. Scores on the RSES range from 10 to 50, with higher scores signifying greater global self-esteem. Robins, Hendin, and Trzesniewski (2001) provide evidence of the reliability and validity of the RSES.

Short Internalized Homonegativity Scale (SIHS). The 12-item SIHS (Currie, Cunningham, \& Findlay, 2004) measures gay men's public identification as gay and their sexual and social comfort with gay men (e.g., "I am comfortable about people finding out that I am gay"). The items were modified to ensure suitability for lesbian women (e.g., "I am comfortable about people finding out that I am gay" became "I am comfortable about people finding out that I am lesbian"). Respondents were asked to indicate their agreement with each statement using a 5-point Likert-type scale ( $1=$ strongly disagree; $2=$ disagree; $3=$ unsure; $4=$ agree; $5=$ strongly agree). Scores on the SIHS range from 12 to 60, with higher scores indicating greater internalized homonegativity. Research by Currie et al. (2004) attests to the psychometric soundness of the SIHS.

Perceived discrimination during lifetime and past 12 months. Based on previous research examining sexual orientation victimization (D'Augelli \& Grossman, 2001; Pilkington \& D'Augelli, 1995), discrimination experiences were assessed using seven items. Specifically, participants were asked if they had ever been verbally insulted, verbally threatened, had their property damaged, objects thrown at them, been physically assaulted, been sexually assaulted, and/or ever been spat on due to their perceived sexual orientation. For this lifetime measure of perceived discrimination, a yes/no response format was used. If a participant responded "yes" to any of the lifetime discrimination items, he/she was then asked to indicate the frequency with which the discriminatory event had occurred in the past 12 months $(0=0$ times; $1=1-2$ times; $2=3-4$ times; 3 = 5-6 times; $4=7+$ times).

Sociodemographics. Participants were asked to provide the following demographic information: age, race/ethnicity (Aboriginal, Asian, Black, Caucasian, Hispanic, Other), birthplace, country currently living in, relationship status (single, dating, living with partner, married, separated/divorced, or partner deceased), and self-perceived integration into the mainstream gay/lesbian community ("I would consider myself to be integrated into the mainstream gay/lesbian community" with response options $1=$ highly; $2=$ moderately; $3=$ mildly; and 4 = not at all). In terms of sexual orientation, respondents had the following options: exclusively homosexual, primarily homosexual, more homosexual than heterosexual, bisexual, more heterosexual than homosexual, primarily heterosexual, or exclusively heterosexual. (Only participants specifying that they were "exclusively homosexual," "primarily homosexual," or "more homosexual than heterosexual" were included in the analyses.) 


\section{Procedure}

A systematic search of Canadian organizations serving sexual minority and gender-minority persons was conducted. Contact was made with a director, supervisor, or leader within each organization, and these individuals were asked whether they would post the link to the survey through their electronic listserv or consent to having a link to the online survey appear on their website. Pride festivals and other sexual- and gender-minority-themed events frequented by sexual minority persons also were targeted within the province in which the research was conducted.

For all recruitment that occurred online, gay and lesbian individuals were invited to participate in the survey after accessing the link through organizational websites or receiving invitations to participate through informal networks. All prospective respondents were provided with an online consent form that, in accordance with ethical guidelines, clearly stipulated that participation was voluntary; responses would be, and remain, confidential; participants would be anonymous (i.e., no personally identifying information was requested); and withdrawal at any time was permissible. Respondents completing pen and paper surveys were provided with a self-addressed envelope so that they could complete the questionnaire at their leisure and mail it back to the researchers. All participants were informed via hard copy or electronically that they had the right to request information about the study and to contact the researchers for a summary of the results or in the event they had questions at any point during the study.

\section{RESULTS}

Means, standard deviations, ranges of scores (possible and obtained), and scale score reliabilities for all key indicants of psychological health can be found in Table 1. According to Radloff and Teri (1986), CES-D scale scores greater than 15 are suggestive of clinically significant depressive symptomatology and, as reported in Lyness et al. (1997), scores above 20 serve as the clinical cut-off for older adults due to the presence of other chronic health conditions occurring later in life. Average total CES-D scores were above 15 for lesbian women only; thus, clinically significant depressive symptomatology may be present in this sample. Total scale scores on the HSCL-21 were below the scale midpoint suggesting that, overall, the sample was not psychologically distressed. Congruent with these findings, both gay men and lesbian women evidenced a relatively optimistic outlook on life and high self-esteem (i.e., mean scores on the LOT and RSES were above the respective scale midpoints). With respect to internalized homonegativity, as measured by the SIHS, participants' mean scores suggest they did not report self-loathing or strong internalization of society's negative messages about being gay or lesbian.

The alpha coefficients for all scales were good to superior, the exception being the measure of internalized homonegativity (i.e., the SIHS). Thus, given elevated random error, all correlations involving the SIHS should be regarded as underestimates.

Independent sample $t$-tests were conducted to determine whether gay and lesbian respondents differed significantly on any indicants of psychological health. No statistically significant differences were obtained (all $p s \geq .20$ ). 
Table 1

Means, Standard Deviations, Ranges, and Alpha Coefficients for All Psychological Health Measures

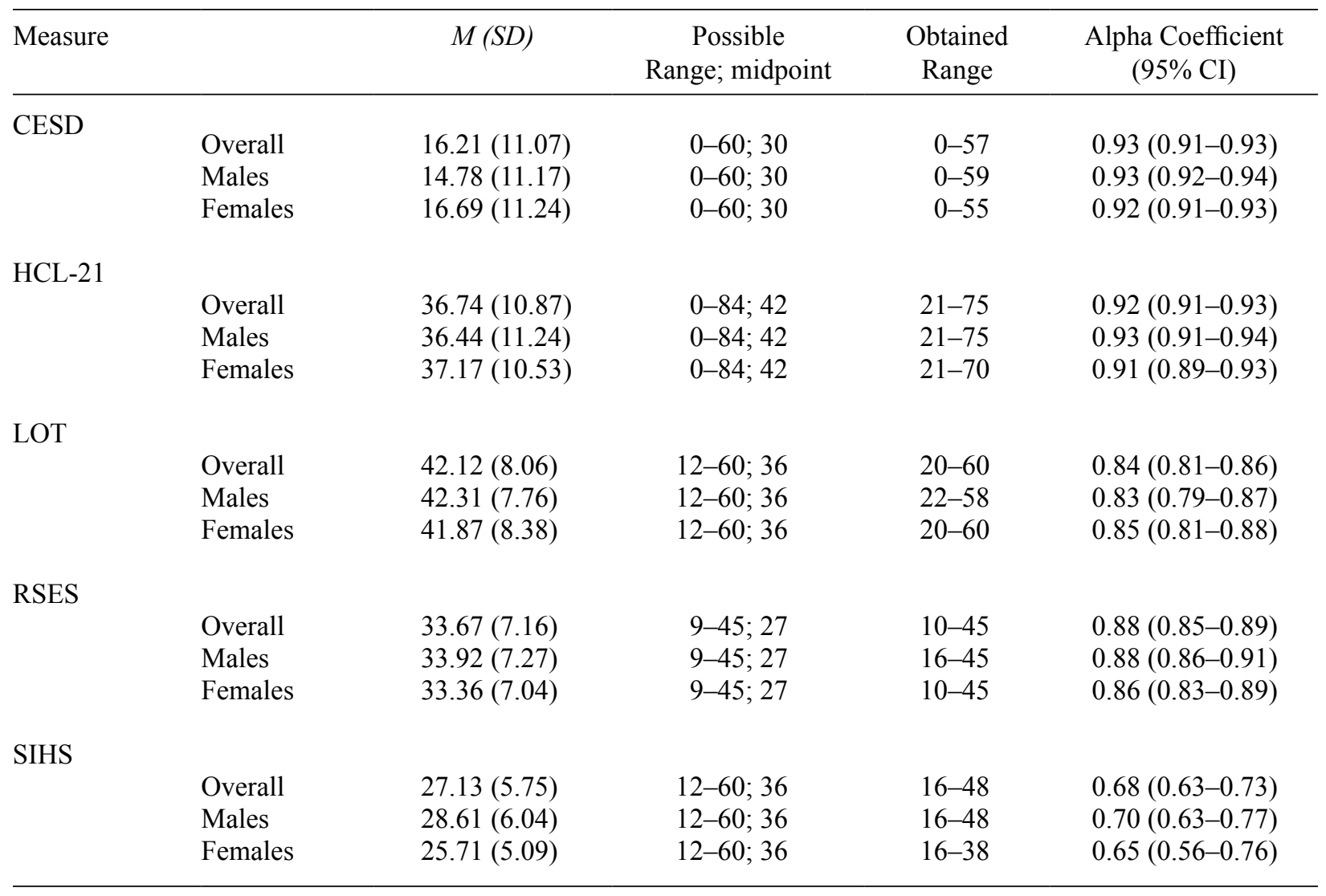

Note: CES-D = Center for Epidemiological Studies-Depression Scale; HSCL-21 = Hopkins Symptom Checklist-21; LOT $=$ Life Optimism Test; RSES $=$ Rosenberg Self-Esteem Scale; SIHS $=$ Short Internalized Homonegativity Scale. For the Rosenberg Self-Esteem Scale, all participants completed the first 9 of the 10 items. Due to an oversight, the 10th item (i.e., "I take a positive attitude toward myself") was completed by fewer than half of the participants in the present study. Independent assessments of the 9-item self-esteem measure were undertaken to examine its alpha coefficient and relationship to key psychological health variables. Results indicated that the 9-item version of self-esteem possessed very good scale score reliability (see above), similar to the 10-item version ( 0.92 , $95 \% \mathrm{CI}=0.88-0.94 ; n=65$ ). All of the correlative patterns obtained for the 9-item version used in this study were replicated in the subsample that completed the 10 -item version.

Intercorrelations among the health variables are provided in Table 2. For gay men, depression and internalized homonegativity were inversely associated with life optimism and self-esteem, and internalized homonegativity correlated positively with psychological distress. For lesbian women, depression, internalized homonegativity, and psychological distress were negatively associated with life optimism and self-esteem. Positive correlations were obtained between internalized homonegativity and depression and psychological distress. 
Table 2

Intercorrelations among Key Psychological Health Variables (Gay Men above the Diagonal; Lesbian Women below the Diagonal)

\begin{tabular}{lccccc}
\hline & CES-D & HSCL-21 & LOT & RSES & SIHS \\
\hline CES-D & & $0.73^{* *}$ & $-0.59^{* *}$ & $-0.67^{* *}$ & 0.16 \\
HSCL-21 & $0.77^{* *}$ & & $-0.61^{* *}$ & $-0.60^{* *}$ & $0.22^{* *}$ \\
LOT & $-0.67^{* *}$ & $-0.58^{* *}$ & & $0.63^{* *}$ & $-0.19^{* *}$ \\
RSES & $-0.65^{* *}$ & $-0.63^{* *}$ & $0.66^{* *}$ & & $-0.28^{* *}$ \\
SIHS & $0.43^{* *}$ & $0.39^{* *}$ & $-0.32^{* *}$ & $-0.33^{* *}$ & \\
\hline
\end{tabular}

Note: $* * p<0.01 ; * p<0.05$. CES-D $=$ Center for Epidemiological Studies-Depression Scale; HSCL-21 $=$ Hopkins Symptom Checklist-21; LOT = Life Optimism Test; RSES = Rosenberg Self-Esteem Scale; SIHS = Short Internalized Homonegativity Scale.

Responses to all discrimination items can be found in Table 3. Endorsement rates suggest that being verbally insulted over the course of one's lifetime emerged as the most frequently cited discriminatory event (75.7\% for men; $83.9 \%$ for women). Indeed, approximately $55.8 \%$ of gay and $63.9 \%$ of lesbian participants reported experiencing this form of discrimination in the last 12 months (range 1 to $7+$ times). Being verbally threatened over the course of one's lifetime was the next most frequently cited discriminatory episode, followed by being the target of a physical assault (less so for lesbian women) and having one's property damaged. Endorsement rates for the remaining discrimination items were (in order): having objects thrown at oneself, being spat on, and being sexually assaulted.

Correlations between psychological health and perceived discrimination are detailed in Table 4. (For interpretative purposes, coefficients of 0.20 or higher may be regarded as possessing practical significance; Ferguson [2009]). Among gay men, psychological distress was positively associated with all forms of discrimination occurring over the course of one's lifetime and during the last 12 months. Depression also was significantly associated with all forms of perceived discrimination, the exceptions being property damage (lifetime and 12 months), objects thrown at oneself (lifetime), being physically assaulted (lifetime), and sexually assaulted (last 12 months). Further, a positive association was found between gay men's level of internalized homonegativity and the likelihood they had been the victim of a sexual assault during their lifetime.

For lesbian women, fewer statistically significant associations were noted. Positive associations were documented, however, between psychological distress and having been verbally threatened over the course of one's lifetime, having one's property damaged (lifetime and last 12 months), and being sexually assaulted (lifetime). Depression also was positively associated with having objects thrown at oneself (lifetime) and being sexually assaulted (lifetime). Finally, internalized homonegativity correlated positively with the likelihood of experiencing sexual assault in the last 12 months. 
Table 3

Frequency of Perceived Discriminatory Events, Stratified by Gender $(N=349 ; n$ for Males $=177 ; \boldsymbol{n}$ for Females $=169)$

\begin{tabular}{|c|c|c|c|}
\hline Discriminatory Event & $\begin{array}{l}\text { Overall } \\
N(\%)\end{array}$ & $\begin{array}{l}\text { Males } \\
n(\%)\end{array}$ & $\begin{array}{c}\text { Females } \\
n(\%)\end{array}$ \\
\hline $\begin{array}{l}\text { Have you been verbally } \\
\text { insulted due to your sexual } \\
\text { orientation? }\end{array}$ & $\begin{array}{l}\text { Yes }=278(79.9) \\
\text { No }=70(20.1)\end{array}$ & $\begin{array}{l}\text { Yes }=134(75.7) \\
\text { No }=43(24.3)\end{array}$ & $\begin{array}{l}\text { Yes }=141(83.9) \\
\text { No }=27(16.1)\end{array}$ \\
\hline $\begin{array}{l}\text { If yes, approximately how } \\
\text { many times in the past } 12 \\
\text { months have you been verbally } \\
\text { insulted? }\end{array}$ & $\begin{array}{l}0 \text { times }=139(39.8) \\
1-2 \text { times }=128(36.7) \\
3-4 \text { times }=44(12.6) \\
5-6 \text { times }=20(5.7) \\
7+\text { times }=18(5.2)\end{array}$ & $\begin{array}{l}0 \text { times }=78(44.1) \\
1-2 \text { times }=62(35.0) \\
3-4 \text { times }=19(10.7) \\
5-6 \text { times }=8(4.5) \\
7+\text { times }=10(5.6)\end{array}$ & $\begin{array}{l}0 \text { times }=61(36.1) \\
1-2 \text { times }=65(38.5) \\
3-4 \text { times }=23(13.6) \\
5-6 \text { times }=12(7.1) \\
7+\text { times }=8(4.7)\end{array}$ \\
\hline $\begin{array}{l}\text { Have you been verbally } \\
\text { threatened due to your sexual } \\
\text { orientation? }\end{array}$ & $\begin{array}{l}\text { Yes }=98(28.4) \\
\text { No }=247(71.6)\end{array}$ & $\begin{array}{l}\text { Yes }=56(32.0) \\
\text { No }=119(68.0)\end{array}$ & $\begin{array}{l}\text { Yes }=42(25.0) \\
\text { No }=126(75.0)\end{array}$ \\
\hline $\begin{array}{l}\text { If yes, approximately how } \\
\text { many times in the past } 12 \\
\text { months have you been verbally } \\
\text { threatened? }\end{array}$ & $\begin{array}{l}0 \text { times }=297(85.1) \\
1-2 \text { times }=42(12.0) \\
3-4 \text { times }=6(1.7) \\
5-6 \text { times }=3(0.9) \\
7+\text { times }=1(0.3)\end{array}$ & $\begin{array}{l}0 \text { times }=151(85.3) \\
1-2 \text { times }=20(11.3) \\
3-4 \text { times }=3(1.7) \\
5-6 \text { times }=3(1.7)\end{array}$ & $\begin{array}{l}0 \text { times }=143(84.6) \\
1-2 \text { times }=22(13.0) \\
3-4 \text { times }=3(1.8) \\
7+\text { times }=1(0.6)\end{array}$ \\
\hline $\begin{array}{l}\text { Have you had your property } \\
\text { damaged due to your sexual } \\
\text { orientation? }\end{array}$ & $\begin{array}{l}\text { Yes }=56(16.1) \\
\text { No }=291(83.9)\end{array}$ & $\begin{array}{l}\text { Yes }=34(19.2) \\
\text { No }=143(80.8)\end{array}$ & $\begin{array}{l}\text { Yes }=20(12.0) \\
\text { No }=147(88.0)\end{array}$ \\
\hline $\begin{array}{l}\text { If yes, approximately how } \\
\text { many times in the past } 12 \\
\text { months have you had your } \\
\text { property damaged? }\end{array}$ & $\begin{array}{l}0 \text { times }=320(91.7) \\
1-2 \text { times }=28(8.0) \\
3-4 \text { times }=1(0.3)\end{array}$ & $\begin{array}{l}0 \text { times }=163(92.1) \\
1-2 \text { times }=13(7.3) \\
3-4 \text { times }=1(0.6)\end{array}$ & $\begin{array}{l}0 \text { times }=155(91.7) \\
1-2 \text { times }=14(8.3)\end{array}$ \\
\hline $\begin{array}{l}\text { Have you had objects thrown } \\
\text { at you due to your sexual } \\
\text { orientation? }\end{array}$ & $\begin{array}{l}\text { Yes }=46(13.3) \\
\text { No }=301(86.7)\end{array}$ & $\begin{array}{l}\text { Yes }=26(14.8) \\
\text { No }=150(85.2)\end{array}$ & $\begin{array}{l}\text { Yes }=19(11.3) \\
\text { No }=149(88.7)\end{array}$ \\
\hline $\begin{array}{l}\text { If yes, approximately how } \\
\text { many times in the past } 12 \\
\text { months have you had objects } \\
\text { thrown at you? }\end{array}$ & $\begin{array}{l}0 \text { times }=332(95.1) \\
1-2 \text { times }=13(3.7) \\
3-4 \text { times }=3(0.9) \\
7+\text { times }=1(0.3)\end{array}$ & $\begin{array}{l}0 \text { times }=168(94.9) \\
1-2 \text { times }=6(3.4) \\
3-4 \text { times }=2(1.1) \\
7+\text { times }=1(0.6)\end{array}$ & $\begin{array}{l}0 \text { times }=162(95.9) \\
1-2 \text { times }=6(3.6) \\
3-4 \text { times }=1(0.6)\end{array}$ \\
\hline
\end{tabular}


Table 3

(Continued)

\begin{tabular}{|c|c|c|c|}
\hline Discriminatory Event & $\begin{array}{l}\text { Overall } \\
N(\%)\end{array}$ & $\begin{array}{l}\text { Males } \\
n(\%)\end{array}$ & $\begin{array}{c}\text { Females } \\
n(\%)\end{array}$ \\
\hline $\begin{array}{l}\text { Have you been physically } \\
\text { assaulted due to your sexual } \\
\text { orientation? }\end{array}$ & $\begin{array}{l}\text { Yes }=47(13.5) \\
\text { No }=301(86.5)\end{array}$ & $\begin{array}{l}\text { Yes }=34(19.3) \\
\text { No }=142(80.7)\end{array}$ & $\begin{array}{l}\text { Yes }=12(7.1) \\
\text { No }=157(92.9)\end{array}$ \\
\hline $\begin{array}{l}\text { If yes, approximately how } \\
\text { many times in the past } \\
12 \text { months have you been } \\
\text { physically assaulted? }\end{array}$ & $\begin{array}{l}0 \text { times }=330(94.6) \\
1-2 \text { times }=15(4.3) \\
3-4 \text { times }=2(0.6) \\
7+\text { times }=2(0.6)\end{array}$ & $\begin{array}{l}0 \text { times }=163(92.1) \\
1-2 \text { times }=10(5.6) \\
3-4 \text { times }=2(1.1) \\
7+\text { times }=2(1.1)\end{array}$ & $\begin{array}{l}0 \text { times }=164(97.0) \\
1-2 \text { times }=5(3.0)\end{array}$ \\
\hline $\begin{array}{l}\text { Have you been sexually } \\
\text { assaulted due to your sexual } \\
\text { orientation? }\end{array}$ & $\begin{array}{l}\text { Yes }=26(7.5) \\
\text { No }=322(92.5)\end{array}$ & $\begin{array}{l}\text { Yes }=15(8.5) \\
\text { No }=162(91.5)\end{array}$ & $\begin{array}{l}\text { Yes }=11(6.5) \\
\text { No }=157(93.5)\end{array}$ \\
\hline $\begin{array}{l}\text { If yes, approximately how } \\
\text { many times in the past } 12 \\
\text { months have you been sexually } \\
\text { assaulted due to your sexual } \\
\text { orientation? }\end{array}$ & $\begin{array}{l}0 \text { times }=344(98.6) \\
1-2 \text { times }=4(1.1) \\
3-4 \text { times }=1(0.3)\end{array}$ & $\begin{array}{l}0 \text { times }=173(97.7) \\
1-2 \text { times }=3(1.7) \\
3-4 \text { times }=1(0.6)\end{array}$ & $\begin{array}{l}0 \text { times }=168(99.4) \\
1-2 \text { times }=1(0.6)\end{array}$ \\
\hline $\begin{array}{l}\text { Have you been spat on due to } \\
\text { your sexual orientation? }\end{array}$ & $\begin{array}{l}\text { Yes }=41(11.8) \\
\text { No }=306(88.2)\end{array}$ & $\begin{array}{l}\text { Yes }=23(13.1) \\
\text { No }=153(86.9)\end{array}$ & $\begin{array}{l}\text { Yes }=18(10.7) \\
\text { No }=150(89.3)\end{array}$ \\
\hline $\begin{array}{l}\text { If yes, approximately how } \\
\text { many times in the past } 12 \\
\text { months have you been spat on } \\
\text { due to your sexual orientation? }\end{array}$ & $\begin{array}{l}0 \text { times }=332(95.1) \\
1-2 \text { times }=12(3.4) \\
3-4 \text { times }=5(1.4)\end{array}$ & $\begin{array}{l}0 \text { times }=171(96.6) \\
1-2 \text { times }=3(1.7) \\
3-4 \text { times }=3(1.7)\end{array}$ & $\begin{array}{l}0 \text { times }=158(93.5) \\
1-2 \text { times }=9(5.3) \\
3-4 \text { times }=2(1.2)\end{array}$ \\
\hline
\end{tabular}

Note: Only response options that had endorsement rates $>0$ are shown.

Multiple regression analyses were conducted to determine the variance in psychological health accounted for by perceived discrimination (i.e., being verbally insulted and verbally threatened over the last 12 months). ${ }^{1}$ In the first MR analysis, depression served as the criterion measure. Because self-esteem predicts depression (Schmitz, Kugler, \& Rollnik, 2003), this variable was treated as a covariate and entered in the first step. For step two, standardized scores for gender, internalized homonegativity, self-perceived integration into gay/ lesbian culture, verbal insults, and verbal threats were entered. Step three consisted of two-way interaction terms: Gender X Internalized Homonegativity; Gender X Self-Perceived Integration into the Gay/Lesbian 


\section{Table 4}

Correlations among Perceived Discrimination and Psychological Health Variables (Males; $\boldsymbol{n}=177$ )

\begin{tabular}{|c|c|c|c|c|c|}
\hline Measures & CES-D & HSCL-21 & LOT & RSES & SIHS \\
\hline Verbal Insult - Lifetime & $0.18 *$ & $0.23 * *$ & -0.14 & -0.12 & 0.08 \\
\hline Verbal Insult - Last 12 months & $0.28 * *$ & $0.41 * *$ & $-0.29 * *$ & -0.15 & -0.03 \\
\hline Verbal Threat - Lifetime & $0.22 * *$ & $0.18^{*}$ & -0.11 & $-0.25 * *$ & -0.02 \\
\hline Verbal Threat - Last 12 months & $0.37 * *$ & $0.45 * *$ & $-0.27 * *$ & $-0.26 * *$ & -0.05 \\
\hline Property Damage - Lifetime & 0.07 & $0.18 *$ & 0.03 & -0.03 & -0.00 \\
\hline Property Damage - Last 12 months & 0.12 & $0.18 *$ & -0.02 & -0.01 & 0.13 \\
\hline Objects Thrown - Lifetime & 0.15 & $0.30 * *$ & -0.11 & -0.10 & -0.03 \\
\hline Objects Thrown - Last 12 months & $0.26 * *$ & $0.39 * *$ & $-0.16^{*}$ & $-0.16^{*}$ & -0.02 \\
\hline Physical Assault - Lifetime & 0.12 & $0.22 * *$ & $-0.16^{*}$ & -0.11 & 0.06 \\
\hline Physical Assault - Last 12 months & $0.20 *$ & $0.37 * *$ & $-0.31 * *$ & $-0.18 *$ & 0.02 \\
\hline Sexual Assault - Lifetime & $0.17 *$ & $0.24 * *$ & $-0.19 *$ & -0.10 & $0.22 * *$ \\
\hline Sexual Assault - Last 12 months & 0.14 & $0.19 *$ & $-0.17 *$ & -0.12 & 0.08 \\
\hline Spat on - Lifetime & $0.20 * *$ & $0.16^{*}$ & $-0.13 *$ & -0.13 & 0.06 \\
\hline Spat on - Last 12 months & $0.23 * *$ & $0.24 * *$ & -0.14 & -0.06 & 0.01 \\
\hline
\end{tabular}

Note: Correlations are statistically significant at $* * p<0.01 ; * p<0.05$. All correlations possessing practical significance $(r \geq 0.20)$ appear in bold. CES-D = Center for Epidemiological Studies on Depression Scale; Distress $=$ Hopkins Symptom Checklist-21; LOT = Life Optimism Test; RSES = Rosenberg Self-Esteem Scale; SIHS = Short Internalized Homonegativity Scale. The correlations between gay men's experience with discriminatory episodes occurring during one's lifetime and past 12 months are as follows: verbal insult, $r(175)=0.47, p<0.01$; verbal threat, $r(173)=0.54, p<0.01$; property damage, $r(173)=0.54, p<0.01$; objects thrown, $r(174)=0.47, p<0.01$; physical assault, $r(174)=0.49, p<0.01$; sexual assault, $r(175)=0.47, p<0.01$; spat on, $r(174)=0.46, p<0.01$. 
Table 4 (Cont'd)

Correlations among Perceived Discrimination and Psychological Health Variables (Females; $n=169$ )

\begin{tabular}{|c|c|c|c|c|c|}
\hline Measures & CES-D & HSCL-21 & LOT & RSES & SIHS \\
\hline Verbal Insult - Lifetime & -0.09 & 0.09 & -0.03 & 0.03 & -0.04 \\
\hline Verbal Insult - Last 12 months & 0.01 & 0.07 & -0.05 & -0.09 & -0.05 \\
\hline Verbal Threat - Lifetime & 0.14 & $0.19 *$ & 0.00 & $-0.16^{*}$ & -0.01 \\
\hline Verbal Threat - Last 12 months & 0.06 & 0.13 & 0.02 & -0.10 & -0.08 \\
\hline Property Damage - Lifetime & 0.09 & $0.19^{*}$ & -0.05 & -0.13 & -0.01 \\
\hline Property Damage - Last 12 months & 0.12 & $0.20 *$ & -0.10 & -0.14 & 0.04 \\
\hline Objects Thrown - Lifetime & $0.15^{*}$ & 0.10 & -0.06 & -0.10 & -0.05 \\
\hline Objects Thrown - Last 12 months & -0.01 & -0.03 & -0.03 & 0.02 & -0.11 \\
\hline Physical Assault - Lifetime & 0.15 & 0.11 & $-0.19 *$ & -0.13 & 0.06 \\
\hline Physical Assault - Last 12 months & 0.06 & 0.03 & -0.07 & -0.05 & 0.06 \\
\hline Sexual Assault - Lifetime & $0.18^{*}$ & $0.18^{* *}$ & -0.08 & -0.11 & 0.08 \\
\hline Sexual Assault - Last 12 months & -0.01 & 0.05 & 0.05 & -0.00 & $0.16^{*}$ \\
\hline Spat on-Lifetime & 0.06 & 0.04 & -0.00 & 0.02 & -0.11 \\
\hline Spat on - Last 12 months & 0.00 & -0.02 & -0.02 & 0.04 & -0.11 \\
\hline
\end{tabular}

Note: Correlations are statistically significant at $* * p<0.01 ; * p<0.05$. All correlations possessing practical significance $(r \geq 0.20)$ appear in bold. CES-D $=$ Center for Epidemiological Studies on Depression Scale; HSCL21 = Hopkins Symptom Checklist-21; LOT $=$ Life Optimism Test; RSES = Rosenberg Self-Esteem Scale; SIHS = Short Internalized Homonegativity Scale. The correlations between lesbian women's experience with discriminatory episodes occurring during one's lifetime and past 12 months are as follows: verbal insult, $r(166)=0.43, p<0.01$; verbal threat, $r(166)=0.65, p<0.01$; property damage, $r(165)=0.82, p<0.01$; objects thrown, $r(166)=0.56, p<$ 0.01 ; physical assault, $r(167)=0.63, p<0.01$; sexual assault, $r(166)=0.29, p<0.01$; spat on, $r(166)=0.72, p<$ 0.01 . 
Community; Gender X Verbal Insults; and Gender X Verbal Threats. The fourth, and final, step involved three-way interaction terms: Gender X Internalized Homonegativity X Verbal Insult; Gender X Internalized Homonegativity X Verbal Threat; Gender X Integration into the Gay/Lesbian Community X Verbal Insult; and Gender X Integration into the Mainstream Gay/Lesbian Community X Verbal Threat. ${ }^{2}$ These interactions would allow one to determine whether: (a) the "consequences" of perceived discrimination differ for gay men and lesbian women; (b) the association between perceived discrimination and psychological health is moderated by internalized homonegativity and/or integration into the gay/lesbian community; and (c) the nature of these moderation effects differs for gay men versus lesbian women (i.e., is the association between discrimination and health stronger for gay men higher in internalized homonegativity or for lesbian women higher in internalized homonegativity?).

MR results indicated that approximately $49 \%\left(\right.$ Adj. $\left.R^{2}=0.49\right)$ of the variance in depression was accounted for by self-esteem, $\beta=-0.60, t=-13.17, p<0.001$; verbal threats, $\beta=0.14, t=2.08, p=0.038$; the Gender X Internalized Homonegativity interaction, $\beta=0.18, t=3.01, p=0.003$; and the Gender X Verbal Insult interaction, $\beta=-0.14, t=-2.21, p=0.028$. This model was statistically significant, $F(10,291)=30.24$, $p<0.001$. The direction of the standardized regression coefficients for the individual correlates suggests that participants who evidence greater self-esteem report lower levels of depression and those who experience greater frequency of verbal threats due to their sexual orientation report being more depressed. To understand the statistically significant Gender X Internalized Homonegativity and Gender X Verbal Insult interactions, separate correlations were conducted for gay men and lesbian women. The correlations between internalized homonegativity and depression were: gay men, $r(151)=0.16, p=\mathrm{ns}$; lesbian women, $r(157)=0.43, p<$ 0.01 . Fisher's $r$ to $Z$-test revealed that the magnitudes of these correlations differed significantly, $z$-value $=$ $2.52, p<0.01$. Thus, the association between internalized homonegativity and depression is stronger for lesbian women. The correlation between verbal insults and depression was 0.28 for gay men $(p<0.01)$ and 0.01 for lesbian women $(p=n s)$. These correlations differed significantly, $z=2.52, p<0.05$, suggesting that, for gay men only, level of depression was associated with experiencing verbal insults.

For the MR analysis using psychological distress as the criterion measure (i.e., standardized scores on the HSCL-21), the same sequence of blocks was tested. Results indicated that the final model was statistically significant, $F(10,291)=33.23, p<0.001$, and accounted for $52 \%$ (Adj. $R^{2}=0.52$ ) of the variance in psychological distress. The following correlates emerged: self-esteem, $\beta=-0.53, t=-11.91, p<0.001$; integration into the gay/lesbian community, $\beta=0.14, t=2.33, p=0.02$; verbal threats, $\beta=0.22, t=3.48, p$ $<0.001$; and a Gender X Verbal Insult interaction, $\beta=-20, t=-3.32, p<0.001$. The direction of the standardized regression coefficients suggests that participants evidencing lower self-esteem and less integration into the gay/lesbian community and experiencing a greater number of verbal threats within the past 12 months reported more psychological distress. With respect to the Gender X Verbal Insult interaction, the correlation between psychological distress and verbal insults was statistically significant for gay men $(r=0.41, p<0$. 01 ), but not for lesbian women, $r=0.07, p=$ ns. Fisher's $r$ to $Z$-test indicated that these correlations differed significantly, $z=3.30, p<0.01 .^{3}$ 


\section{DISCUSSION}

To the author's knowledge, no published study has examined the associations among adult Canadian gay men and lesbian women's psychological health and their discriminatory experiences. To begin addressing the critical omission of Canadian-based research on this topic, the present study documented: (a) the prevalence of gay- and lesbian-experienced discrimination in the form of verbal insults; verbal threats; property damage; objects thrown at participants; physical assault; sexual assault; and being spat on; and (b) the linkage between gay- and lesbian-experienced discrimination and indicants of psychological health, namely, depression, psychological distress, life-optimism, self-esteem, and internalized homonegativity. It was anticipated that verbal insults and threats would be the most frequently cited types of discrimination experienced by gay and lesbian participants. It also was anticipated that experiencing discrimination would be positively related to depression and psychological distress and inversely related to life-optimism and self-esteem.

As anticipated, for gay men and lesbian women, verbal insults and verbal threats due to one's sexual orientation emerged as the most frequently cited discrimination experiences. Over three-quarters of the men and women sampled had been verbally insulted, with more than one-quarter reporting they had been the target of a verbal threat due to their sexual orientation. The other forms of discrimination occurring over the course of participants' lifetime were cited with notable frequency. For gay men, these experiences were (in descending order): being physically assaulted; having one's property damaged; having objects thrown at oneself by others; being spat on; and being sexually assaulted. For lesbian women, these experiences were: having one's property damaged; having objects thrown at oneself by others; being spat on; being physically assaulted; and being sexually assaulted.

Several statistically significant correlations emerged between participants' discrimination experiences and the indicants of psychological health. On average, gay men who had experienced discrimination also evidenced greater depression. Similar albeit weaker associations emerged between discrimination and psychological distress and depression for lesbian women. Where significant associations emerged between discrimination and life optimism and self-esteem, the relationships were in the anticipated direction; thus, the greater one's experience with discrimination, the lower one's life optimism and self-esteem. It should be noted, however, that only a small subset of these correlations met the standard criterion for practical significance: gay men $(k=21)$ and lesbian women $(k=1)$.

Exploratory multiple regression analyses also were conducted. Importantly, the associations between depression and psychological distress and the experience of verbal insults were significantly greater in magnitude for gay men than lesbian women. One possible explanation for this finding is that the prospect and actual event of being insulted verbally may be more distressing for gay men than for lesbian women. That is, women who are lesbian may be more likely to be verbally insulted (and this was evidenced in the present study) due, perhaps, to their dual-role as women and lesbians within an arguably patriarchal society that privileges men. As a consequence, women may find themselves more sensitized to this form of "mundane" homonegativity (Peel, 2001) and less likely to be distressed when it occurs.

Also, the association between internalized homonegativity and depression was significantly greater in magnitude for lesbian women than gay men. This finding suggests that internalized homonegativity was keenly felt by the lesbian women who participated in the study and the linkage between internalized 
homonegativity and depression for this subsample was fairly robust. In an effort to better understand why such associations exist, research examining the ways in which internalized homonegativity affects the psychological and physical health of lesbian women should be conducted. According to Peterson and Gerrity (2006) and Szymanski and Chung (2003), there is a paucity of research currently on the role internalized homonegativity plays in the lives of lesbian women. A specific impediment in this field of research surrounds the measurement of the construct. Indeed, a limitation associated with the present study was its reliance on a measure of internalized homonegativity (i.e., the SIHS) that pertained to gay men. Thus, researchers should aim to incorporate measures of internalized homonegativity designed specifically for lesbian women, such as the Lesbian Internalized Homophobia Scale (LIHS; Szymanski \& Chung, 2001), ${ }^{4}$ a step that may provide additional insight into the relevance and maintenance of this social force in the lives of women who self-identify as lesbian.

This study possesses several limitations that warrant discussion. First, participants were recruited from a variety of different settings across the country and the prevalence rates of discrimination reported should not be viewed as representative of the general Canadian population of gay men and lesbian women. Another source of bias centres on the fact that all data were obtained via self-report. Meyer (2003a) explicates various challenges associated with the collection of self-reported discrimination experiences, namely, problems arising due to retrospective recall and appraisals. It is logical to posit that certain individuals will perceive various events as being less or more discriminatory than others, and enact coping mechanisms that can lead to under- and over-estimations of discrimination. A third limitation is reliance on discrimination items that are overt in nature. According to Jewell, McCutcheon, Harriman, and Morrison (2011), most of the research that documents the experiences of gay men and lesbian women has focused on overt forms of discrimination (e.g., Herek, Gillis, Cogan, \& Glunt, 1997; Herek, 2009), with little attention paid to documenting and understanding the subtle manifestations of anti-gay/-lesbian bias. Emerging evidence from a number of qualitative studies (e.g., Jewell \& Morrison, 2010; Kitzinger, 2005; Morrison \& Morrison, 2002; Peel, 2001; Speer \& Potter, 2000) suggests that sexual minority group members face a series of subtle forms of discrimination. Given the frequency with which subtle discrimination may be perpetrated and the detrimental effects thought to be associated with this type of discrimination (Silverschanz, Cortina, Konik, \& Magley, 2008; Swim, Johnston, \& Pearson, 2009; Waldo, 1999), the dearth of research pertaining to subtle homonegativity reflects a critical omission in the literature. Researchers should consider measurement of covert discrimination a high priority, particularly given the environments in which various contemporary forms of homonegativity are likely to occur (e.g., modern homonegative attitudes and behaviours in university settings; Morrison, Kenny, \& Harrington, 2005; Morrison \& Morrison, 2011; Morrison, Morrison, \& Franklin, 2009).

Further, with respect to overt discrimination, the way in which participants perceived certain items is unclear (e.g., verbal insult items occurring over the course of one's lifetime or in the past 12 months). For instance, whether respondents reported the extent to which they were direct targets of a verbal insult or the extent to which they heard phrases that were insulting such as "that's so gay" is unknown. A greater degree of precision should be employed by researchers when assessing these types of perceived discrimination.

Regardless of the nature of the episodes, it is important to mention that within the research area of discrimination based on sexual orientation there has been considerable reliance on measures that possess unsatisfactory psychometric properties and/or research that reports statistical decision making that is 
sub-optimal. In a recent systematic review of sexual orientation-related discrimination measures, Morrison, Morrison, Jewell, and McDermott (2011) report that many instruments are developed on an ad hoc basis with insufficient attention paid to their construct validity, and researchers compute total scores without testing scale score reliability and assume that items form typologies (verbal versus physical) without testing dimensionality. The absence of a "gold standard" measure makes it difficult to synthesize studies and, in so doing, formulate a coherent understanding of the literature.

In conclusion, the gay men and lesbian women who participated in this study reported experiencing considerable discrimination across the seven forms that were assessed. The types of discrimination reported by lesbian women and gay men also correlated in the anticipated directions with variables denoting psychological health. To establish a Canadian body of research, documentation of overt, covert, and institutional forms of discrimination (e.g., Hatzenbuehler, Keyes, \& Hasin, 2009) against sexual minorities should be undertaken. Finally, determining the associations between various forms of discrimination experienced by sexual minorities and indicants of psychological and physical health warrants ongoing empirical attention.

\section{RÉSUMÉ}

Malgré l'augmentation du nombre d'études qui examinent le lien entre la discrimination ressentie et l'état de santé psychologique, les études de ce type sont rares au Canada. Afin de combler ce manque, notre étude décrit la fréquence d'évènements discriminatoires éprouvés par les minorités sexuelles et leur association avec des indicateurs de bien-être psychologique. Dans le cadre d'une enquête en ligne, 348 hommes qui se déclarent homosexuels $(n=177)$ et femmes qui se déclarent lesbiennes $(n=169)$ ont répondu à des mesures sur la discrimination ressentie, la dépression, le stress psychologique, l'optimisme et l'estime de soi. Les incidents le plus souvent cités sont la perception d'insultes et de menaces verbales, et plusieurs corrélats de dépression et de stress psychologique se dégagent comme étant statistiquement significatifs. Des analyses préliminaires suggèrent que: (a) l'association entre la dépression et l'homonégativité intériorisée est de plus grande ampleur pour les lesbiennes que pour les homosexuels et (b) les associations entre le fait d'être la cible d'insultes verbales et la dépression ainsi que le stress psychologique est plus importante pour les homosexuels que pour les lesbiennes. Les limites de l'étude ainsi que des pistes de recherche sont discutées.

Mots clés : homosexuels, lesbiennes, préjugés, discrimination, stigma, santé, homonégativité, homophobie, Canada

\section{NOTES}

1. Verbal insults and verbal threats, in that order, were found to be the most frequently cited forms of perceived discrimination. Although the remaining five perceived discrimination items are highly meaningful, on the basis of statistical grounds, only verbal insults and verbal threats were included in the regression analyses.

2. For both regression models, the inclusion of block four (i.e., the three-way interactions) did not account for incremental variance and thus will not be discussed further.

3. It is possible that the sequelae of verbal insults and verbal threats may differ as a function of whether they are distal (i.e., within one's lifetime) or proximal (i.e., within the last 12 months). MR analyses were re-run using lifetime verbal insults and verbal threats. When depression served as the criterion measure, the significant predictors were identical (with the exception of verbal threat emerging in the 12-month model). When distress served as the criterion measure, the significant predictors were identical, with the exception of internalized homonegativity emerging in the lifetime model and verbal threat and the Gender X Verbal Insult interaction emerging for the 12-month model.

4. Unfortunately, Szymanski and Chung's (2001) measure of internalized homonegativity for lesbian women could not be used due to length considerations. 


\section{REFERENCES}

Adam, B. (1999). Moral regulation and the disintegrating Canadian state. In B. Adam, J.W. Duyvendak, \& A. Krouwel (Eds.), The global emergence of gay and lesbian politics: National imprints of a worldwide movement (pp. 12-29). Philadelphia, PA: Temple University Press.

Chae, D.H., Krieger, N., Bennett, G.G., Lindsey, J.C., Stoddard, A.M., \& Barbeau, E.M. (2010). Implications of discrimination based on sexuality, gender, and race/ethnicity for psychological distress among working-class sexual minorities: The United for Health Study, 2003-2004. International Journal of Health Services, 40(4), 589-608.

Cepeda-Benito, A., \& Gleaves, D.H. (2000). Cross-ethnic equivalence of the Hopkins Symptom Checklist-21 in European American, African American, and Latino college students. Cultural Diversity and Ethnic Minority Psychology, 6(3), 297-308.

Cochran, S., \& Mays, V.M. (2007). Physical health complaints among lesbians, gay men, and bisexual and homosexually experienced heterosexual individuals: Results from the California Quality of Life Survey. American Journal of Public Health, 97(11), 2048-2055.

Currie, M.R., Cunningham, E.G., \& Findlay, B.M. (2004). The Short Internalized Homonegativity Scale: Examination of the factorial structure of a new measure of internalized homophobia. Educational and Psychological Measurement, 64(6), 1053-1067.

D’Augelli, A.R. (2003). Lesbian and bisexual female youths aged 14-21: Developmental challenges and victimization experiences. Journal of Lesbian Studies, 7(4), 9-29.

D'Augelli, A.R., \& Grossman, A.H. (2001). Disclosure of sexual orientation, victimization, and mental health among lesbian, gay, and bisexual older adults. Journal of Interpersonal Violence, 16(10), 1008-1027.

Derogatis, L.R., Lipman, R.S., Rickels, K., Uhlenhuth, E., \& Covi, L. (1974). The Hopkins Symptom Checklist (HSCL): A self-report inventory. Behavioral Science, 19(1), 1-15.

Ferguson, C.J. (2009). An effect size primer: A guide for clinicians and researchers. Professional Psychology: Research and Practice, 40(5), 532-538.

Fingerhut, A.W., Peplau, L.A., \& Gable, S.L. (2010). Identity, minority stress, and psychological well-being among gay men and lesbians. Psychology \& Sexuality, 1(2) 101-114.

Green, D.E., Walkey, F.H., McCormick, I.A., \& Taylor, A.J.W. (1988). Development and evaluation of a 21-item version of the Hopkins Symptom Checklist with New Zealand and United States respondents. Australian Journal of Psychology, 40(1), 61-70.

Hatzenbuehler, M.L. (2009). How does sexual minority stigma "get under the skin"? A psychological mediation framework. Psychological Bulletin, 135(5), 707-730.

Hatzenbuehler, M.L., Keyes, K.M., \& Hasin, D.S. (2009). State-level policies and psychiatric morbidity in lesbian, gay, and bisexual populations. American Journal of Public Health, 99(12), 2275-2281.

Hatzenbuehler, M.L., McLaughlin, K.A., Keyes, K.M., \& Hasin, D.S. (2010). The impact of institutional discrimination on psychiatric disorders in lesbian, gay, and bisexual populations: A prospective study. American Journal of Public Health, 100(3), 452-459.

Herek, G.M. (2009). Hate crimes and stigma-related experiences among sexual minority adults in the United States. Journal of Interpersonal Violence, 24(1), 54-74.

Herek, G.M., Gillis, J.R., Cogan, J.C., \& Glunt, E.K. (1997). Hate crime victimization among lesbian, gay, and bisexual adults: Prevalence, psychological correlates, and methodological issues. Journal of Interpersonal Violence, 12(2), 195-117.

Jewell, L.M., McCutcheon, J., Harriman, R.L., \& Morrison, M.A. (2011). "It's like a bunch of mosquitoes coming at you...": Exploring the ubiquitous nature of subtle discrimination and its implications for the everyday experiences of LGB individuals. In T.G. Morrison, M.A. Morrison, M. Carrigan, \& D.T. McDermott (Eds.), Sexual minority research in the new millennium (pp. 157-186). Hauppauge, NY: Nova Science Publishers.

Jewell, L.M., \& Morrison, M.A. (2010). "But there's a million jokes about everybody...": Prevalence of, and reasons for directing, negative behaviors toward gay men on a Canadian university campus. Journal of Interpersonal Violence, 25(1), 2094-2112.

Kitzinger, C. (2005). Heteronormativity in action: Reproducing the heterosexual nuclear family in after-hours medical calls. Social Problems, 52(4), 477-498. 


\section{PSYCHOLOGICAL, HEALTH CORRELATES}

Lewinsohn, P.M., Seeley, J.R., Roberts, R.E., \& Allen, N.B. (1997). Center for Epidemiologic Studies Depression Scale (CES-D) as a screening instrument for depression among community-residing older adults. Psychology \& Aging, 12(6), 277-287.

Lyness, J.M., Noel, T.K., Cox, C., King, D.A., Conwell, Y., \& Caine, E.D. (1997). Screening for depression in elderly primary care patients: A comparison of the Center for Epidemiologic Studies-Depression Scale and the Geriatric Depression Scale. Archives of Internal Medicine, 157(4), 449-454.

Mays, V.M. \& Cochran, S.D. (2001). Mental health correlates of perceived discrimination among lesbian, gay, and bisexual adults in the United States. American Journal of Public Health, 91(11), 1869-1876.

Meyer, I. (2003a). Prejudice as stress: Conceptual and measurement problems. American Journal of Public Health, 93(2), 262-265.

Meyer, I. (2003b). Prejudice, social stress, and mental health in lesbian, gay, and bisexual populations: Conceptual issues and research evidence. Psychological Bulletin, 129(5), 674-697.

Morrison, T.G., Kenny, P., \& Harrington, A. (2005). Modern prejudice toward gay men and lesbian women: Assessing the viability of a measure of modern homonegative attitudes within an Irish context. Genetic, Social, and General Psychology Monographs, 131(3), 219-250.

Morrison, M.A., \& Morrison, T.G. (2002). Development and validation of a scale measuring modern prejudice toward gay men and lesbian women. Journal of Homosexuality, 43(2), 15-37.

Morrison, M.A., \& Morrison, T.G. (2011). Sexual orientation bias toward gay men and lesbian women: Modern homonegative attitudes and their association with discriminatory behavioural intentions. Journal of Applied Social Psychology, 41(11), 2573-2599.

Morrison, M.A., Morrison, T.G., \& Franklin, R. (2009). Modern and old-fashioned homonegativity among samples of Canadian and American university students. Journal of Cross-Cultural Psychology, 40(4), 523-542.

Morrison, M.A., Morrison, T.G., Jewell, L.M., \& McDermott, D. (2011). A psychometric review of measures assessing discrimination against sexual minorities. Manuscript in preparation.

Pascoe, E.A., \& Richman, L.S. (2009). Perceived discrimination and health: A meta-analytic review. Psychological Bulletin, 135(4), 531-554.

Peel, E. (2001). Mundane heterosexism: Understanding incidents of the everyday. Women's Studies International Forum, 24(5), 541-554.

Peterson, T.L., \& Gerrity, D.A. (2006). Internalized homophobia, lesbian identity development, and self-esteem in undergraduate women. Journal of Homosexuality, 50(4), 49-75.

Pilkington, N.W., \& D'Augelli, A.R. (1995). Victimization of lesbian, gay, and bisexual youth in community settings. Journal of Community Psychology, 23(1), 33-56.

Radloff, L.S. (1977). The CES-D Scale: A self-report depression scale for research in the general population. Applied Psychological Measurement, 1(3), 385-401.

Radloff, L.S., \& Teri, L. (1986). Use of the Center for Epidemiologic Studies-Depression Scale with other adults. Clinical Gerontologist, 5(1-2), 119-136.

Roberts, A.L., Austin, S.B., Corliss, H.L., Vandermorris, A.K., \& Koenen, K.C. (2010). Pervasive trauma exposure among US sexual orientation minority adults and risk of posttraumatic stress disorder. American Journal of Public Health, 100(12), 2433-2441.

Robins, R.W., Hendin, H.M., \& Trzesniewski, K.H. (2001). Measuring global self-esteem: Construct validation of a single-item measure and the Rosenberg Self-Esteem Scale. Personality and Social Psychology Bulletin, 27(2), 151-161.

Rosenberg, M. (1965). Society and the adolescent self-image. Princeton, NJ: Princeton University Press.

Savin-Williams, R. (2001). Suicide attempts among sexual-minority youths: Population and measurement issues. Journal of Consulting and Clinical Psychology, 69(6), 983-991.

Scheier, M.F., \& Carver, C.S. (1985). Optimism, coping, and health: Assessment and implications of generalized outcome expectancies. Health Psychology, 4(3), 219-247.

Schmitz, N., Kugler, J., \& Rollnik, J. (2003). On the relation between neuroticism, self-esteem, and depression: Results from the National Comorbidity Survey. Comprehensive Psychiatry, 44(3), 169-175.

Silverschanz, P., Cortina, L.M., Konik, J., \& Magley, V.J. (2008). Slurs, snubs, and queer jokes: Incidence and impact of heterosexist harassment in academia. Sex Roles, 58(3-4), 179-191. 
Speer, S.A., \& Potter, J. (2000). The management of heterosexist talk: Conversational resources and prejudiced claims. Discourse and Society, 11(4), 543-572.

Swim, J.K., Johnston, K., \& Pearson, N.B. (2009). Daily experiences with heterosexism: Relations between heterosexist hassles and psychological well-being. Journal of Social and Clinical Psychology, 28(5), 597-629.

Szymanski, D.M., \& Chung, Y.B. (2001). The Lesbian Internalized Homophobia Scale. Journal of Homosexuality, 41(2), 37-52.

Szymanski, D.M., \& Chung, B.Y. (2003). Internalized homophobia in lesbians. Journal of Lesbian Studies, 7(1), 115-125.

Waldo, C.R. (1999). Working in a majority context: A structural model of heterosexism as minority stress in the workplace. Journal of Counseling Psychology, 46(2), 218-232. 